\title{
Interactions Between Meloidogyne artiellia, the Cereal and Legume Root-Knot Nematode, and Fusarium oxysporum f. sp. ciceris Race 5 in Chickpea
}

\author{
Pablo Castillo, Juan A. Navas-Cortés, David Gomar-Tinoco, Mauro Di Vito, and Rafael M. Jiménez-Díaz
}

\begin{abstract}
First, second, and third authors: Instituto de Agricultura Sostenible (IAS), Consejo Superior de Investigaciones Científicas (CSIC), Apdo. 4084, 14080 Córdoba, Spain; fourth author: Istituto per la Protezione delle Piante, Sezione di Bari: Nematologia Agraria, Consiglio Nazionale delle Ricerche (CNR), Via G. Amendola 165/A, 70126 Bari, Italy; and fifth author: IAS-CSIC and Escuela Técnica Superior de Ingenieros Agrónomos y Montes, Apdo. 3048, 14080 Córdoba, Spain.
\end{abstract}

Accepted for publication 3 July 2003.

\begin{abstract}
Castillo, P., Navas-Cortés, J. A., Gomar-Tinoco, D., Di Vito, M., and Jiménez-Díaz, R. M. 2003. Interactions between Meloidogyne artiellia, the cereal and legume root-knot nematode, and Fusarium oxysporum f. sp. ciceris race 5 in chickpea. Phytopathology 93:1513-1523.

In the Mediterranean Basin, Fusarium oxysporum f. sp. ciceris and the root-knot nematode Meloidogyne artiellia coinfect chickpea. The influence of root infection (after inoculation with 20 nematode eggs and second-stage juveniles per gram of soil) by two M. artiellia populations, from Italy and Syria, on the reaction of chickpea lines and cultivars with partial resistance to Fusarium wilt (CA 252.10.1.OM, CA 255.2.5.0, CPS 1, and PV 61) and with complete resistance to $F$. oxysporum f. sp. ciceris race 5 (CA 334.20.4, CA 336.14.3.0, ICC $14216 \mathrm{~K}$, and UC 27) was investigated under controlled conditions. In genotypes with partial resistance, infection by $M$. artiellia significantly increased the severity of Fusarium wilt, irrespective of the fungal inoculum density $(3,000$ or

F. oxysporum f. sp. ciceris race 5 in CA 334.20.4 and CA 336.14.3.0 but not in ICC $14216 \mathrm{~K}$, irrespective of the fungal inoculum density, and overcame the resistance in UC 27 only at the higher inoculum density. Infection by the nematode significantly increased the number of propagules of $F$. oxysporum f. sp. ciceris race 5 in root tissues of genotypes with complete resistance to Fusarium wilt, compared with roots that were not inoculated with the nematode, irrespective of the fungal inoculum density, except in ICC $14216 \mathrm{~K}$, in which this effect occurred only at the higher inoculum density. Reproduction of an M. artiellia population from Syria in the absence of $F$. oxysporum f. sp. ciceris race 5 was significantly higher than that of a population from Italy in all tested chickpea genotypes except ICC 14216 K. However, there was no significant difference between the reproduction rates of the two nematode populations in plants infected with $F$. oxysporum $\mathrm{f}$. sp. ciceris race 5, irrespective of the fungal inoculum density and the reaction of the genotypes to the fungus.
\end{abstract} 30,000 chlamydospores per gram of soil), except in cultivar CPS 1 at the lower fungal inoculum density. In genotypes with complete resistance to Fusarium wilt, infection by $M$. artiellia overcame the resistance to
Additional keywords: breakdown of race-specific resistance, Cicer arietinum, fungus-nematode interaction.
Fusarium wilt diseases are managed primarily by planting resistant cultivars (35). However, coinfection of plants by fungi inducing Fusarium wilt and root-knot nematodes may risk valuable resistance to the interacting fungus and increase disease severity in susceptible cultivars $(9,15,18,20,30)$.

Fusarium wilt caused by Fusarium oxysporum f. sp. ciceris, the most important soilborne pathogen of chickpea in the Indian subcontinent, the Mediterranean Basin, and California $(2,21,24)$, is managed primarily by planting cultivars with race-specific resistance $(22,24,25)$. Research in our laboratory led to development of chickpea lines with either complete or partial resistance to $F$. oxysporum $\mathrm{f}$. sp. ciceris race 5 (34), the most virulent race occurring in Spain $(25,27)$. This resistance was derived from a different source from that used in the development of other cultivars reported to be resistant to Fusarium wilt $(2,3,25)$.

Studies in India have shown that interactions of $F$. oxysporum f. sp. ciceris and Meloidogyne incognita or M. javanica in chickpea can lead to a breakdown of resistance to an unidentified race of the Fusarium wilt pathogen $(28,31,45,46)$. Those root-knot

Corresponding author: P. Castillo; E-mail address: ag1cascp@uco.es

Publication no. P-2003-0925-01R

(C) 2003 The American Phytopathological Society nematodes, however, do not infect chickpea in Spain (6). However, severe attacks by the cereal and legume root-knot nematode, $M$. artiellia, have been reported in chickpea in Spain and other countries of the Mediterranean Basin (10,43). In these countries, populations of $M$. artiellia in commercial field soils were found to range from 0.05 to 1.8 second-stage juveniles (J2s) and eggs per cubic centimeter $(6,12)$. The optimal temperature for $M$. artiellia is lower than that for $M$. incognita and $M$. javanica (11), and $M$. artiellia reproduces well on cereals, cruciferous plants, and legumes, with the exception of oat, corn, and lentil $(13,39)$. Many crops susceptible to $M$. artiellia are widely used in rotations in the Mediterranean Basin, which may provide a means of maintaining high populations of the nematode in soil. Therefore, it is possible for $F$. oxysporum f. sp. ciceris and $M$. artiellia to occur together in chickpea fields (6) and infect chickpea plants jointly. Consequently, there is a need to assess whether infection of chickpea by $M$. artiellia can break Fusarium wilt resistance in the newly developed chickpea lines mentioned above and whether these lines can be used to develop wilt-resistant cultivars. However, no information could be found about coinfection of chickpea by $F$. oxysporum f. sp. ciceris and $M$. artiellia. The objectives of this study were to determine (i) the effects of infection by $M$. artiellia on the reaction of chickpea lines and cultivars with complete or partial resistance to $F$. oxysporum $\mathrm{f}$. sp. ciceris race 5 and (ii) whether such effects would be influenced by the genetic background of the resistant plants. 


\section{MATERIALS AND METHODS}

Inocula of pathogens and plant material. The monoconidial isolate Foc 8012 of F. oxysporum f. sp. ciceris race 5 used in this study was collected from infected chickpea in southern Spain and was characterized in previous studies $(26,29,32)$. Isolate Foc 8012 was stored in sterile soil at $4^{\circ} \mathrm{C}$. Active cultures were obtained by placing small aliquots of the stored material on a plate of fresh potato-dextrose agar (250 $\mathrm{g}$ of unpeeled potatoes, $20 \mathrm{~g}$ of agar, and $20 \mathrm{~g}$ of glucose per liter of distilled water) and incubating for 7 days at $25^{\circ} \mathrm{C}$ with a 12-h photoperiod of fluorescent and nearUV light at $36 \mu \mathrm{E} \mathrm{m}^{-2} \mathrm{~s}^{-1}$. The fungal inoculum used in the experiments consisted of chlamydospores of $F$. oxysporum f. sp. ciceris race 5 produced in a soil mixture. To produce the inoculum, the fungus was increased in a cornmeal-sand mixture incubated as described above for 2 weeks (44). The infested cornmeal-sand was then thoroughly mixed $(1: 12, \mathrm{wt} / \mathrm{wt})$ with a soil mixture (sand/ loam, $1: 1$, vol/vol) that had been autoclaved twice (at $121^{\circ} \mathrm{C}$, for $1 \mathrm{~h}$ each time), and the resulting mixture was distributed in $1,000-\mathrm{ml}$ Erlenmeyer flasks (400 g in each flask) and incubated at $25^{\circ} \mathrm{C}$ in darkness for 6 weeks. The production of chlamydospores in the infested soil was confirmed by microscopic observations. Soil containing chlamydospores was stored at $4^{\circ} \mathrm{C}$ until use, for a maximum of 4 weeks. The number of chlamydospores of per gram of infested soil mixture was determined by dilution plating on V8 juice-oxgall-pentachloronitrobenzene agar (VOPA), a Fusariumselective medium (33), just before use. The infested soil was thoroughly mixed with a soil mixture (sand/clay loam, 2:1, vol/vol) that had been autoclaved twice (at $121^{\circ} \mathrm{C}$, for $1 \mathrm{~h}$ each time), in the appropriate proportion to obtain an inoculum density of 3,000 or 30,000 chlamydospores per gram.

The $M$. artiellia populations used in this study were collected from roots of infected chickpea in fields at Monopoli, Italy (population $M a-\mathrm{I}$ ), and Tel-Hadya, Syria (population $M a-\mathrm{S}$ ). A single egg mass of $M$. artiellia was removed from an individual gall, containing a single female nematode, on an infected chickpea root. Egg masses were surface-disinfested with $1 \% \mathrm{NaOCl}$ for $4 \mathrm{~min}$ and then washed four times in sterile distilled water. A single egg mass was placed on roots of a 2- to 3-week-old UC 27 chickpea plant grown in the autoclaved soil mixture, and plants were incubated for 3 to 4 months at $21 \pm 1^{\circ} \mathrm{C}$ with a 14 -h photoperiod of fluorescent light at $360 \pm 25 \mu \mathrm{E} \mathrm{m} \mathrm{m}^{-2} \mathrm{~s}^{-1}$. Nematode inocula for experiments consisted of eggs increased by the same procedures and under the same conditions described above. Eggs were extracted by means of the $\mathrm{NaOCl}$ procedure (23). Briefly, roots of chickpea infected with $M$. artiellia were thoroughly washed in tap water, cut into segments 1 to $2 \mathrm{~cm}$ long, and agitated in $1 \% \mathrm{NaOCl}$ for $3 \mathrm{~min}$. Then, the suspension was screened consecutively through sieves with $75-\mu \mathrm{m}$ and $5-\mu \mathrm{m}$ openings. Eggs retained on the sieve with $5-\mu \mathrm{m}$ openings were washed several times and resuspended in sterile distilled water. The number of eggs in the suspension was determined from 1-ml aliquots of a serial dilution of the suspension, and the nematode inoculum density was adjusted with sterile distilled water.

The following chickpea lines and cultivars were selected for study, on the basis of complete or partial resistance to $F$. oxysporum f. sp. ciceris race 5, determined in previous studies: (i) lines CA 334.20.4, CA 336.14.3.0 (34), and ICC 14216 K (R. M. JiménezDíaz, unpublished data) and cultivar UC 27 (2), having complete resistance, and (ii) lines CA 252.10.1.OM and CA 255.2.5.0 (34) and cultivars CPS 1 and PV 61 (25,27), having partial resistance. The susceptibility of all of these genotypes to M. artiellia Ma-I and $M a-S$ has been confirmed.

Growth chamber experiments. Three experiments (I to III) were conducted in a growth chamber adjusted to $25 \pm 1{ }^{\circ} \mathrm{C}$, at 60 to $90 \%$ relative humidity, with a 14 -h photoperiod of fluorescent light at $360 \pm 25 \mu \mathrm{Em}^{-2} \mathrm{~s}^{-1}$. These environmental conditions are optimal for the development of Fusarium wilt in chickpea $(25,29)$ and favorable for the reproduction of $M$. artiellia (11). Chickpea seeds were surface-disinfested with $2 \% \mathrm{NaOCl}$ for $3 \mathrm{~min}$ and germinated on sterile, moistened filter paper in petri plates at $25^{\circ} \mathrm{C}$ in darkness for 48 to $72 \mathrm{~h}$. Germinated seeds, selected for uniformity (with radicles 1 to $2 \mathrm{~cm}$ long), were sown in $15-\mathrm{cm}$ diameter clay pots (one seed per pot) filled with $0.5 \mathrm{~L}$ of the autoclaved soil mixture infested or not infested with the pathogens. The potted plants were watered as needed and fertilized with 100 $\mathrm{ml}$ of a $0.1 \%$ solution of a $20-5-32+$ micronutrients hydro-sol fertilizer (Haifa Chemicals, Haifa, Israel) every week.

In experiment I, we determined the effects of moderate inoculum density of $F$. oxysporum f. sp. ciceris race 5 (3,000 chlamydospores per gram of soil) alone or combined with inoculum of $M$. artiellia $M a$-I or $M a-S$ on the development of Fusarium wilt. Chickpea lines CA 334.20.4 and ICC $14216 \mathrm{~K}$ and cultivar UC 27 (with complete resistance to this $F$. oxysporum f. sp. ciceris race 5) and line CA 252.10.1.OM and cultivars CPS 1 and PV 61 (with partial resistance to race 5) were tested in this experiment. Germinated seeds were sown in the autoclaved soil infested with 0 or 3,000 chlamydospores of $F$. oxysporum f. sp. ciceris race 5 per gram of soil and with 0 or 20 eggs and J2s per cubic centimeter of soil. The six treatments were (i) uninfested soil; (ii) soil infested with $M$. artiellia $M a-S$; (iii) soil infested with $M$. artiellia $M a-\mathrm{I}$; (iv) soil infested with $F$. oxysporum f. sp. ciceris race 5; (v) soil infested with $M$. artiellia $M a-\mathrm{S}$ and $F$. oxysporum f. sp. ciceris race 5; and (vi) soil infested with $M$. artiellia $M a$-I and $F$. oxysporum $\mathrm{f}$. sp. ciceris race 5 . The nematode inoculum was added in $10 \mathrm{ml}$ of sterile distilled water at the time of sowing. Sterile distilled water $(10 \mathrm{ml})$ was added in treatments without the nematode. The inoculum density of $F$. oxysporum $\mathrm{f}$. sp. ciceris race 5 in the infested soil was determined by dilution plating on VOPA Fusarium-selective medium just before sowing.

In experiment I there was low disease reaction in cultivar CPS 1 (partially resistant) and no disease developed in line ICC $14216 \mathrm{~K}$ and cultivar UC 27 (completely resistant). Therefore, in experiment II, a higher inoculum density of $F$. oxysporum f. sp. ciceris race 5 and the same inoculum density of $M$. artiellia $M a$-I and $M a-\mathrm{S}$ were used. The chickpea genotypes used in experiment II were CA 255.2.5.0, CA 334.20.4, CPS 1, PV 61, UC 27, and ICC $14216 \mathrm{~K}$. Treatments in this experiment were the same as in experiment I, except $F$. oxysporum f. sp. ciceris race 5 was added at inoculum densities of 0 or 30,000 chlamydospores per gram of soil. Inoculations were conducted as described for experiment I.

In experiment III, we compared the effect of both moderate and high inoculum densities of $F$. oxysporum $\mathrm{f}$. sp. ciceris race 5 alone or combined with inoculum of $M$. artiellia $M a-\mathrm{I}$ or $M a-S$ on the development of Fusarium wilt in resistant chickpeas. Lines CA 334.20.4 and CA 336.14.3.0 and cultivar UC 27, with complete resistance to Fusarium wilt, and the partially resistant cultivar PV 61 were tested. Plants were inoculated with $F$. oxysporum f. sp. ciceris race 5 at three inoculum densities (0, 3,000, and 30,000 chlamydospores per gram soil) and with each of the $M$. artiellia populations at two inoculum densities ( 0 and 20 eggs and J2s per cubic centimeter of soil). The experiment was of a factorial treatment design comprising nine inoculation treatment combinations per line or cultivar. The inoculations were carried out as described for experiment I.

Each of the three experiments was arranged in a completely randomized design with 10 replicates, each replicate consisting of a single potted plant. The experiments lasted 60 to 62 days after inoculation.

Disease assessment and data analysis. The incidence and severity of Fusarium wilt were assessed at 2- to 3-day intervals until the end of the experiments. The severity of symptoms on individual plants was rated on a scale of 0 to 4 according to the percentage of foliage with yellowing or necrosis $(0=0 \% ; 1=1$ to $33 \%$; $2=34$ to $66 \% ; 3=67$ to $100 \%$; and $4=$ death of the plant) (26). The incidence of foliar symptoms $(I)$, rated 0 or 1 , and severity 
data $(S)$, rated from 0 to 4 , were used to calculate a disease intensity index $(D I I)(7,33)$ as follows: $D I I=(I \times S) / 4$. Disease progress curves were obtained from the accumulated $D I I$ over time in days from the date of sowing. For each treatment, the standardized area under the disease progress curve (SAUDPC) was calculated by a trapezoidal integration method and standardized by the duration of disease development (expressed in days) (4). Additionally, an incubation period $(I P)$ for disease development was established as the number of days until $D I I>0$.

Upon termination of the experiments, isolations were made from the second and eighth stem internodes of symptomless plants to determine the occurrence of vascular infection by $F$. oxysporum f. sp. ciceris race 5 . Stem sections $1 \mathrm{~cm}$ long were surface-disinfested in $0.4 \% \mathrm{NaOCl}$ for $1 \mathrm{~min}$, blotted dry on sterile filter paper, plated on VOPA, and incubated for 5 to 7 days at $25^{\circ} \mathrm{C}$ with a 12-h photoperiod of fluorescent and near-UV light at $36 \mu \mathrm{E} \mathrm{m}^{-2} \mathrm{~s}^{-1}$.

The nematode population density in both soil and roots was also assessed for each replicate at the end of the experiments. Nematodes were extracted from $100-\mathrm{cm}^{3}$ samples of soil by centrifugal flotation (8). Soil was washed through a sieve with $710-\mu$ m openings, the filtered water was collected in a beaker and thoroughly mixed with $4 \%$ kaolin by volume, and the mixture was centrifuged at $1,500 \times g$ for $4 \mathrm{~min}$. Pellets were resuspended in $250 \mathrm{ml}$ of $\mathrm{MgSO}_{4}(\delta=1.16)$, and the suspension was centrifuged at $1,500 \times$ $g$ for $3 \mathrm{~min}$. Supernatants were passed through a sieve with $5-\mu \mathrm{m}$ openings, and nematodes collected on the sieve were washed with tap water, transferred to petri dishes, and counted under a stereomicroscope (8). To assess nematode population density in roots, the complete root system of a plant was washed free of soil and cut into 1- to 2-cm segments, and nematodes were extracted from a 5-g sample by maceration followed by centrifugation. Root tissues in $250 \mathrm{ml}$ of a $1 \%$ solution of $\mathrm{NaOCl}$ were homogenized in a Waring blender at 6,300 rpm for $1 \mathrm{~min}$, and homogenates were centrifuged and extracted as described above (8). Population den- sities were used to calculate the reproduction index $(\mathrm{Rf}=$ final population density divided by initial population density). The severity of nematode galling of roots was not assessed, because infection by $M$. artiellia $M a-\mathrm{I}$ and $M a-\mathrm{S}$ did not cause visible symptoms on roots (10).

F. oxysporum f. sp. ciceris race 5 in roots of inoculated plants was quantified at the end of the experiments as CFU per gram of fresh root tissue by dilution-plating on VOPA and incubating as described above for 5 to 7 days.

Data from uninoculated control treatments and from treatments involving Fusarium wilt-resistant lines and cultivars that showed no wilt symptoms were not included in analyses of Fusarium wilt severity. Similarly, treatments without $M$. artiellia were not included in analyses of nematode reproduction, to avoid the use of zero in analysis of variance. All nematode population densities were transformed to $\log _{10}(x+1)$. Orthogonal single degree of freedom contrasts were computed to test the effect of selected experimental treatment combinations (16).

\section{RESULTS}

No wilt symptoms developed in either the control plants uninfested with Fusarium or in cultivar UC 27 and lines CA 334.20.4, CA 336.14.3.0, and ICC $14216 \mathrm{~K}$ (having complete resistance to Fusarium wilt) in the absence of $M$. artiellia inoculum, irrespective of the inoculum density of $F$. oxysporum f. sp. ciceris race 5 in experiments I to III (Figs. 1-3 and Tables 1-3). Also, in symptomless plants, no vascular infection by $F$. oxysporum f. sp. ciceris race 5 was detected by isolations from stem tissues.

In experiment I, the severity of Fusarium wilt in the absence of the nematode, determined by the DII and SAUDPC, was similar for cultivars CPS 1 and PV 61 and line CA 252.10.1.OM, which are partially resistant to Fusarium wilt (Table 1). Coinfection of

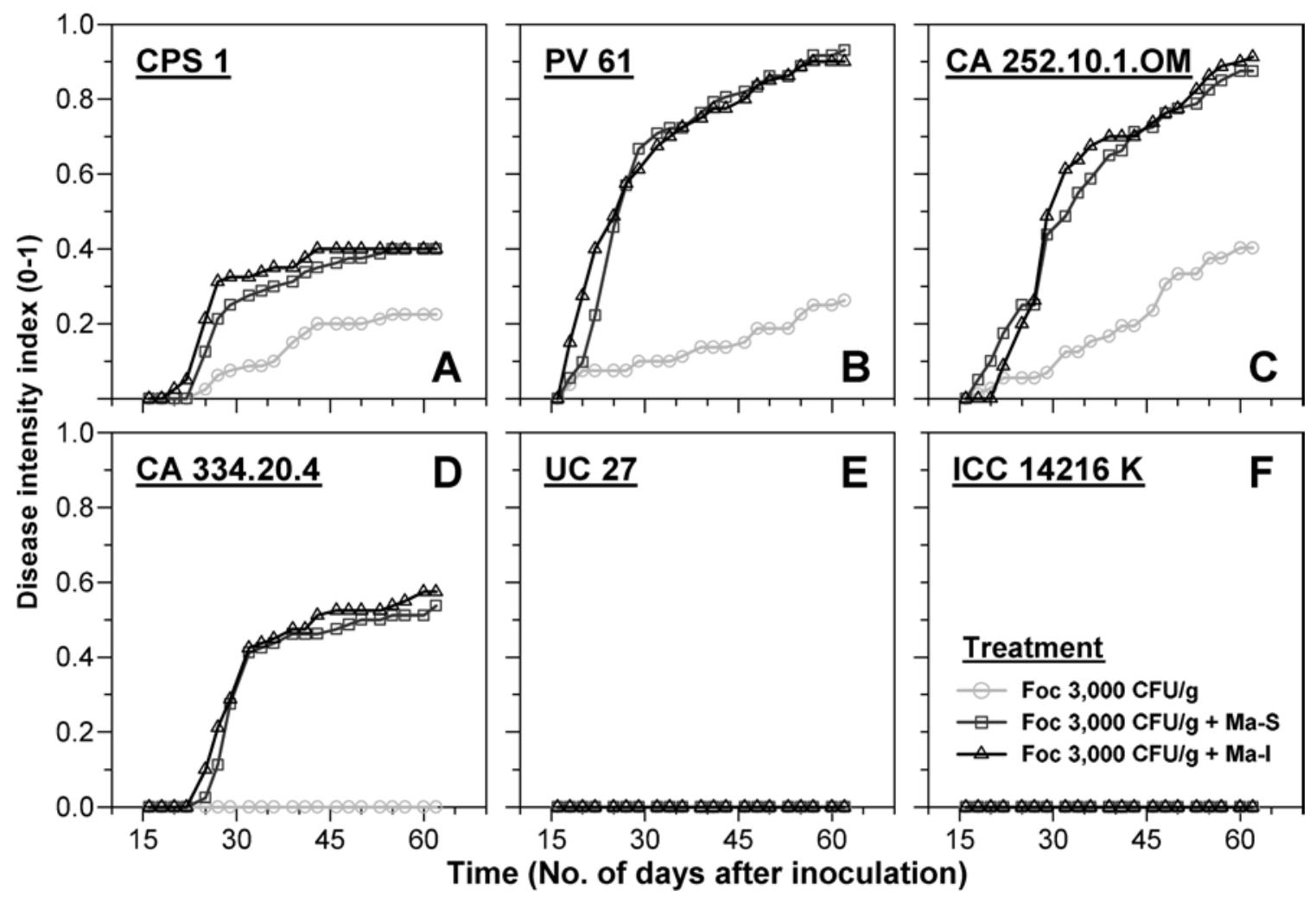

Fig. 1. Progress of Fusarium wilt in chickpea genotypes with partial resistance to the disease (CPS 1, PV 61, and CA 252.10.1.OM) and genotypes with complete resistance (CA 334.20.4, UC 27, and ICC $14216 \mathrm{~K}$ ) simultaneously inoculated with of Fusarium oxysporum f. sp. ciceris race 5 (3,000 chlamydospores per gram of soil) and Meloidogyne artiellia populations from Italy (Ma-I) and Syria (Ma-S) (20 eggs and second-stage juveniles per cubic centimeter of soil). Each point is the mean disease intensity index of 10 replicate plants, each replicate consisting of a single potted plant. 
those genotypes with $F$. oxysporum $\mathrm{f}$. sp. ciceris race 5 and either $M$. artiellia $M a-\mathrm{I}$ or $M a-\mathrm{S}$ significantly increased $(P<0.05) \mathrm{Fu}-$ sarium wilt severity in PV 61 and CA 252.10.1.OM, but not in CPS 1, compared with disease reaction in the absence of the nematode (Fig. 1A-C and Table 1). Fusarium wilt severity in CPS 1 coinfected with the fungus and the nematode was increased, compared with disease severity in the absence of the nematode, but the difference was not significant $(P=0.642)$. In these three genotypes, coinfection by the two pathogens significantly reduced $(P<$ $0.05)$ the incubation period $(I P)$ of Fusarium wilt. The reduction in IP was significant $(P<0.05)$ in CPS 1 and PV 61 infected with $M$. artiellia $M a-\mathrm{I}$ and in CA 252.10.1.OM infected with either $M$. artiellia $M a$-I or $M a-\mathrm{S}$ (Table 1). In chickpea genotypes with complete resistance to Fusarium wilt, coinfection with $F$. oxysporum f. sp. ciceris race 5 and $M$. artiellia $M a-\mathrm{I}$ or $M a-S$ resulted in the breakdown of resistance in CA 334.20.4 but not in ICC $14216 \mathrm{~K}$ and UC 27 (Fig. 1D-F and Table 1). There were no vascular infections by the fungus in the stems of symptomless resistant plants. In CA 334.20.4, wilt symptoms appeared about 3 weeks after inoculation, and disease developed to reach a final DII higher than that in the partially resistant cultivar CPS 1 coinfected with the two pathogens (Fig. 1D and Table 1). However, in genotypes with complete resistance, root infection by $F$. oxysporum f. sp. ciceris race 5, as determined by CFU per gram of root tissue, was significantly increased $(P<0.05)$ by coinfection with either $M$. artiellia $M a$-I or $M a$-S, except in ICC $14216 \mathrm{~K}$, in which populations of $F$. oxysporum $\mathrm{f}$. sp. ciceris race 5 reproduced to the same extent $(P=$ 0.355 ) with or without coinfection (Table 1 ). Nematode reproduction in the absence of the fungus in the partially resistant genotypes was significantly influenced $(P<0.02)$ by the geographic origin of the nematode inoculum in cultivar CPS 1 and line CA 252.10.1.OM, but not in PV 61, with $M$. artiellia $M a$-S reproducing better than $M a$-I (Table 1). In genotypes with partial resistance to Fusarium wilt, nematode reproduction and fungal colonization in root tissues of plants infected by the fungus were not assessed, because of severe impairment of most of the root system as a result of severe wilt (Table 1).

The inoculum density of $F$. oxysporum $\mathrm{f}$. sp. ciceris race 5 in experiment II was increased to 30,000 chlamydospores of per gram of soil to further assess the stability of complete resistance to Fusarium wilt in ICC $14216 \mathrm{~K}$ and UC 27 under higher fungal inoculum pressure in plants infected with $M$. artiellia. Compared with the inoculum density in experiment I, the higher level of fungal inoculum in the absence of the nematode increased Fusarium wilt severity in the partially resistant chickpea genotypes. The increase was greater in PV 61 than in CPS 1 (Tables 1 and 2, Fig. 1A and B, and Fig. 2A and B). Line CA 255.2.5.0 was more susceptible to $F$. oxysporum $\mathrm{f}$. sp. ciceris race 5 at high inoculum density than CPS 1 and PV 61. As in experiment I, coinfection of partially resistant genotypes by $F$. oxysporum f. sp. ciceris race 5 and either $M$. artiellia $M a$-I or $M a$-S significantly increased $(P<$ $0.05)$ the severity of Fusarium wilt, determined by the DII and SAUDPC, compared to the severity of infection by $F$. oxysporum f. sp. ciceris race 5 alone. However, in contrast to experiment I, coinfection with the two pathogens reduced $(P<0.05)$ the Fusarium wilt $I P$ in PV 61 and CPS 1, but not in CA 255.2.5.0 (Fig. $2 \mathrm{~A}-\mathrm{C}$ and Table 2). The breakdown of complete resistance to Fusarium wilt in CA 334.20 .4 by coinfection with the nematode, observed in experiment I, also occurred in experiment II; in addition, the higher fungal inoculum density in the latter experiment resulted in an increase in the severity of Fusarium wilt, from 43 to $74 \%$ in the DII and from 26 to $56 \%$ in the SAUDPC, compared with the results of experiment I (Tables 1 and 2). The greater fungal inoculum density also resulted in a breakdown of the complete resistance to Fusarium wilt in UC 27 infected by the nematode, which did not occur with the lower inoculum density used in experiment I. Disease severity in UC 27 was comparable to that in the partially resistant CPS 1 in the absence of the nematode, par-
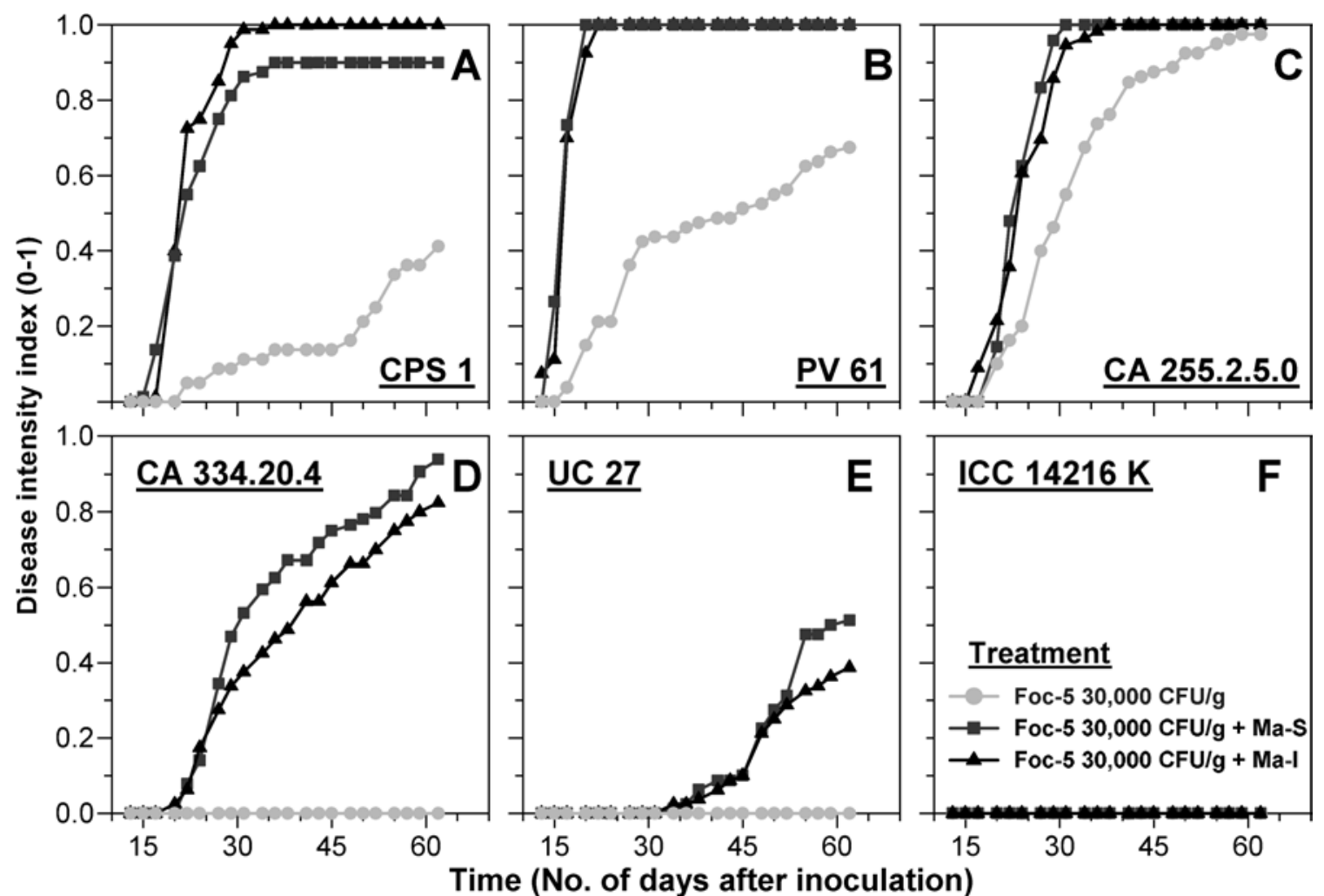

Fig. 2. Progress of Fusarium wilt in chickpea genotypes with partial resistance to the disease (CPS 1, PV 61, and CA 255.2.5.0) and genotypes with complete resistance (CA 334.20.4, UC 27, and ICC 14216 K) simultaneously inoculated with Fusarium oxysporum f. sp. ciceris race 5 (30,000 chlamydospores per gram of soil) and Meloidogyne artiellia populations from Italy (Ma-I) and Syria (Ma-S) (20 eggs and second-stage juveniles per cubic centimeter of soil). Each point is the mean disease intensity index of 10 replicate plants, each replicate consisting of a single potted plant. 
ticularly when UC 27 was coinfected with $F$. oxysporum f. sp. $c$ iceris race 5 and $M$. artiellia $M a$-I (Fig. $2 \mathrm{~A}$ and $\mathrm{E}$ and Table 2). However, the complete resistance of ICC $14216 \mathrm{~K}$ held, even with the high fungal inoculum density used in experiment II, regardless of the nematode population. Furthermore, no vascular infection was found in stems of symptomless plants of ICC $14216 \mathrm{~K}$. As in experiment I, in genotypes with complete resistance to Fusarium wilt, coinfection with $F$. oxysporum f. sp. ciceris race 5 and either $M$. artiellia $M a-\mathrm{I}$ or $M a-\mathrm{S}$ significantly increased $(P<0.05)$ root infection by the fungus, as determined by CFU per gram of root tissue (Table 2). As in experiment I, in cultivars with partial resistance to Fusarium wilt, root infection by $F$. oxysporum f. sp. $c i$ ceris race 5 was not determined, because most plants died of wilt before the end of the experiment (Table 2). Compared with experiment I, the reproduction of $M$. artiellia $M a-\mathrm{S}$ in experiment II in the absence of the fungus was significantly higher $(P<0.05)$ than that of M. artiellia $M a-\mathrm{I}$ in all genotypes with partial or complete resistance to Fusarium wilt, with the exception of ICC 14216 K, in which $M$. artiellia $M a-\mathrm{S}$ and $M a$-I reproduced to the same extent (Table 2). As in experiment I, root infection by $F$. oxysporum f. sp. ciceris race 5 did not influence nematode reproduction in the genotypes with complete resistance to Fusarium wilt, except in UC 27, in which coinfection by $F$. oxysporum $\mathrm{f}$. sp. ciceris race 5 and $M$. artiellia $\mathrm{Ma}-\mathrm{S}$ significantly reduced $(P=0.003)$ nematode reproduction (Table 2).

Overall, Fusarium wilt development in experiment III, as indicated by the $I P, D I I$, and SAUDPC values in susceptible reactions, was comparable to that in experiments I and II for the same chickpea genotypes and fungal inoculum densities (Tables 1-3). Results of the third experiment confirmed that the breakdown of complete resistance to Fusarium wilt in UC 27 in coinfection by $F$. oxysporum $\mathrm{f}$. sp. ciceris race 5 and $M$. artiellia requires a high fungal inoculum density; however, coinfection with much less fungal inoculum overcame complete resistance to Fusarium wilt in CA 334.20.4 and in the newly tested CA 336.14.3.0 (Figs. 1-3 and Table 3). Also, as in experiments I and II, the severity of Fusarium wilt in the partially resistant PV 61 , as estimated by the DII and SAUDPC, was significantly increased $(P<0.05)$ by coinfection with $F$. oxysporum f. sp. ciceris race 5 and either $M$. artiellia $M a-\mathrm{I}$ or $M a-S$ (Figs. 1-3 and Table 3). In experiment III, Fusarium wilt severity in PV 61 increased steadily with the increase in fungal inoculum in the absence of the nematode, and it increased further when plants were jointly infected with the two pathogens (Fig. 3A). However, disease severity in the completely resistant CA 336.14.3.0 and CA 334.20.4 coinfected with $F$. oxysporum f. sp. ciceris race 5 and $M$. artiellia was not increased by the increase in fungal inoculum density (Fig. 3C and D and Table 3). In plants with complete resistance to Fusarium wilt in experiment III, as in experiments I and II, coinfection by $F$. oxysporum f. sp. ciceris race 5 and $M$. artiellia consistently increased root infection by the fungus, as determined by CFU per gram of root tissue, irrespective of the fungal inoculum density (Table 3). The reproduction rate of $M$. artiellia in each of the chickpea genotypes tested in experiment III was of the same order of magnitude found in ex-

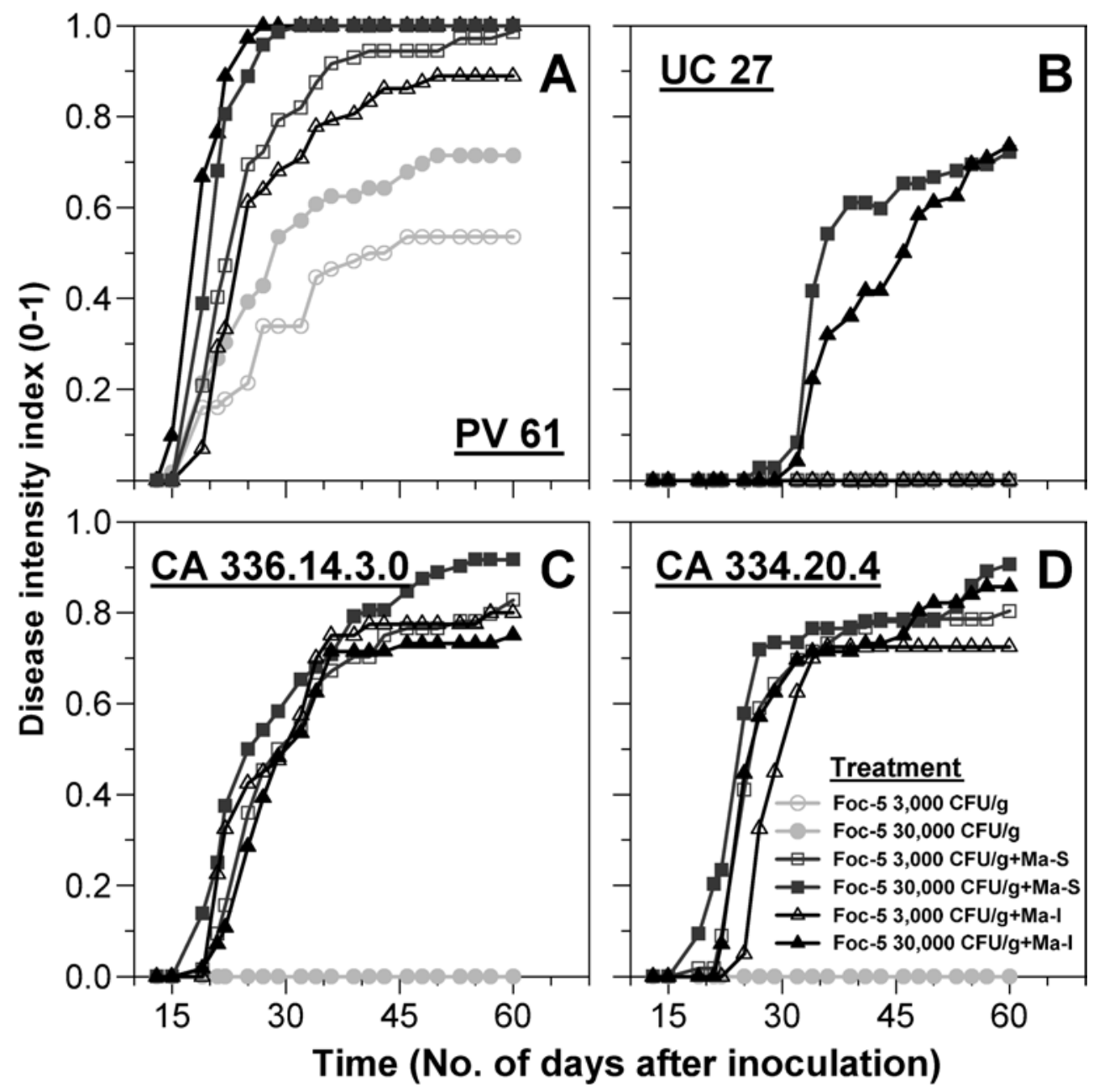

Fig. 3. Progress of Fusarium wilt in a chickpea genotype with partial resistance to the disease (PV 61) and genotypes with complete resistance (UC 27, CA 336.14.3.0, and CA 334.20.4) simultaneously inoculated with Fusarium oxysporum f. sp. ciceris race 5 (either 3,000 or 30,000 chlamydospores per gram of soil) and Meloidogyne artiellia populations from Italy (Ma-I) and Syria (Ma-S) (20 eggs and second-stage juveniles per cubic centimeter of soil). Each point is the mean disease intensity index of 10 replicate plants, each replicate consisting of a single potted plant. 
periments I and II. Also, the nematode reproduction rate in the absence of $F$. oxysporum $\mathrm{f}$. sp. ciceris race 5 was consistently greater for $M$. artiellia $M a-S$ than for $M$. artiellia $M a-\mathrm{I}$, irrespective of the reaction of the chickpea genotypes to Fusarium wilt (Table 3), and root infection by $F$. oxysporum $\mathrm{f}$. sp. ciceris race 5 did not significantly influence $(P \geq 0.05)$ nematode reproduction (Table 3).

\section{DISCUSSION}

Fusarium wilt in chickpea can be managed by the use of racespecific resistant cultivars and by the choice of a sowing date $(24,33)$. However, efficient management of the disease requires that the influence of other potential pathogens be assessed (33). Infection of plants by root-knot nematodes can strongly influence

TABLE 1. Effect of Fusarium oxysporum f. sp. ciceris race 5 and Meloidogyne artiellia populations Ma-I and Ma-S in simultaneous inoculation of chickpea genotypes with partial resistance and genotypes with complete resistance to Fusarium wilt in the first growth chamber experiment ${ }^{\mathrm{a}}$

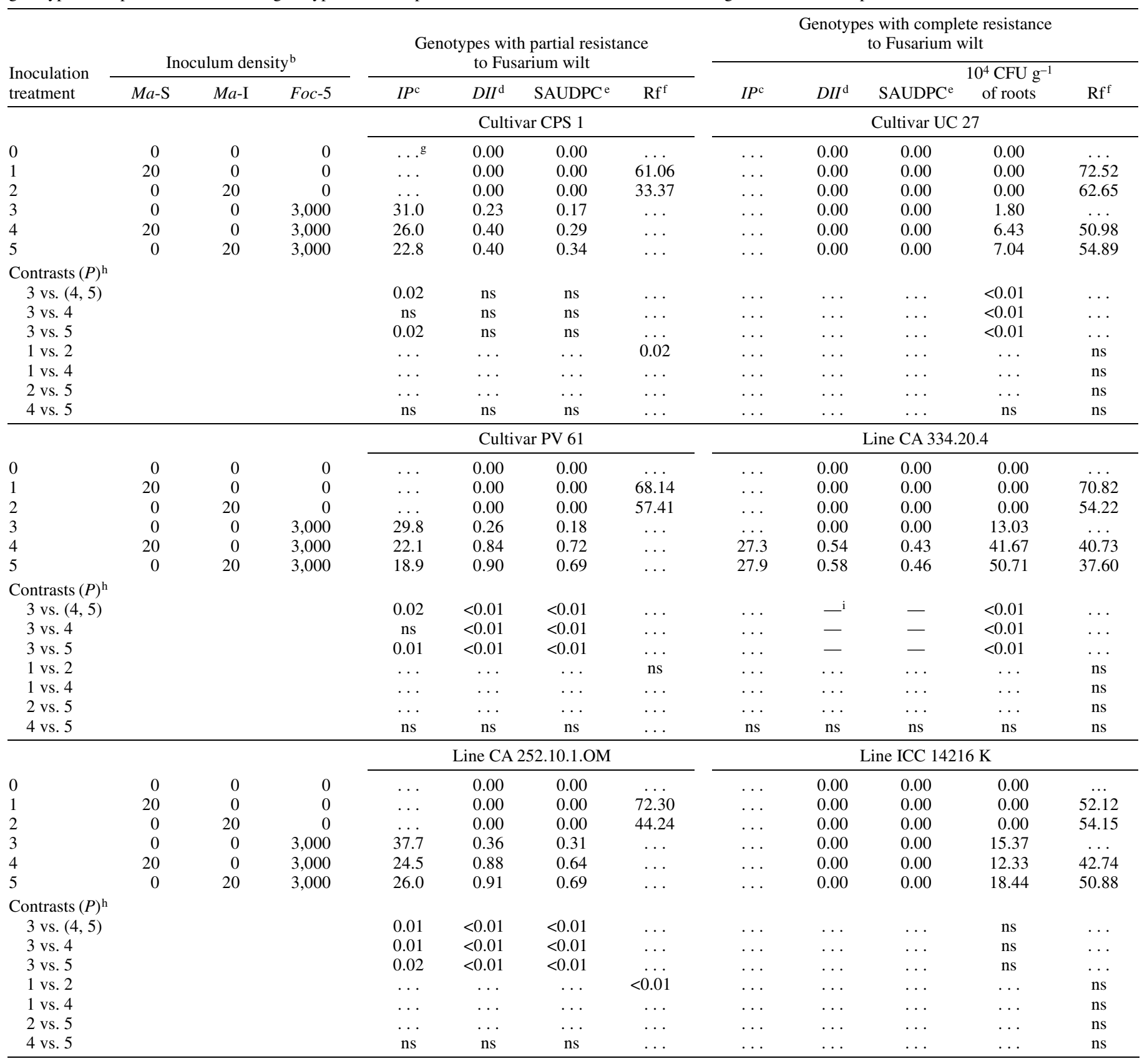

${ }^{a}$ Data are the means of results for 10 replicate plants per treatment combination.

${ }^{\mathrm{b}}$ For M. artiellia populations $M a-\mathrm{S}$ (from Syria) and $M a$-I (from Italy), inoculum density is the number of eggs and second-stage juveniles per cubic centimeter of soil. For F. oxysporum f. sp. ciceris race 5 (Foc-5), inoculum density is the number of chlamydospores per gram of soil.

c $I P=$ incubation period, expressed as the number of days from inoculation until $D I I>0$.

${ }^{\mathrm{d}} D I I=$ disease intensity index, calculated on the last day of assessment, 62 days after inoculation.

e SAUDPC $=$ area under the disease progress curve standardized by duration (in days) of the epidemic.

${ }^{\mathrm{f}} \mathrm{Rf}=$ nematode reproduction rate, defined as the final nematode population density per plant divided by the initial nematode population density per plant. Data were transformed to $\log (x+1)$ for analysis.

g Not tested.

${ }^{\mathrm{h}}$ Orthogonal contrast of inoculation treatments. Probability for the $t$ statistic of linear single degree of freedom contrasts; ns $=$ not significant $(P>0.05)$. In plants with partial resistance to Fusarium wilt, severe impairment of most of the root system of wilted plants made it impossible to assess nematode reproduction in and fungal colonization of root tissues, and consequently some contrasts could not be made.

i The comparison was not performed, to avoid the use of zero in the orthogonal contrast. 
the incidence, degree of symptom expression, and yield losses caused by Fusarium wilt $(1,15,30)$. This study was designed to determine whether infection of chickpea roots by the cereal and legume root-knot nematode, $M$. artiellia, influences the reaction of chickpea genotypes with complete or partial resistance to the highly virulent race 5 of $F$. oxysporum $\mathrm{f}$. sp. ciceris and whether the influence depends on the inoculum density of $F$. oxysporum f. sp. ciceris race 5 .
Results from repeated growth chamber experiments using moderate and high fungal inoculum densities were reproducible and clearly demonstrate that in chickpea genotypes with partial resistance to Fusarium wilt the severity of the disease was significantly increased by coinfection with $F$. oxysporum f. sp. ciceris race 5 and $M$. artiellia. This effect occurred regardless of the inoculum density of $F$. oxysporum f. sp. ciceris race 5 and the geographic origin (Italy or Syria) of the populations of M. artiellia used in

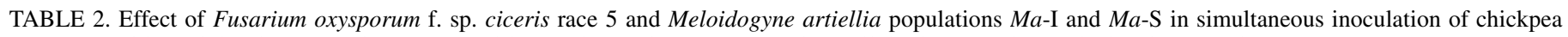
genotypes with partial resistance and genotypes with complete resistance to Fusarium wilt in the second growth chamber experiment ${ }^{\mathrm{a}}$

\begin{tabular}{|c|c|c|c|c|c|c|c|c|c|c|c|c|}
\hline \multirow{3}{*}{$\begin{array}{l}\text { Inoculation } \\
\text { treatment }\end{array}$} & \multirow{2}{*}{\multicolumn{3}{|c|}{ Inoculum density $^{\mathrm{b}}$}} & \multirow{2}{*}{\multicolumn{4}{|c|}{$\begin{array}{l}\text { Genotypes with partial resistance } \\
\text { to Fusarium wilt }\end{array}$}} & \multicolumn{5}{|c|}{$\begin{array}{c}\text { Genotypes with complete resistance } \\
\text { to Fusarium wilt }\end{array}$} \\
\hline & & & & & & & & & & & $10^{4} \mathrm{CFU} \mathrm{g}^{-1}$ & \\
\hline & \multirow[t]{2}{*}{$M a-\mathrm{S}$} & \multirow[t]{2}{*}{$M a-\mathrm{I}$} & \multirow[t]{2}{*}{ Foc-5 } & $I P^{\mathrm{c}}$ & $D I I^{\mathrm{d}}$ & SAUDPC $^{\mathrm{e}}$ & $\operatorname{Rf}^{f}$ & $I P^{\mathrm{c}}$ & $D I I^{\mathrm{d}}$ & SAUDPC $^{\mathrm{e}}$ & of roots & $\mathrm{Rf}^{\mathrm{f}}$ \\
\hline & & & & \multicolumn{4}{|c|}{ Cultivar CPS 1} & \multicolumn{5}{|c|}{ Cultivar UC 27} \\
\hline 0 & 0 & 0 & 0 & $\ldots g$ & 0.00 & 0.00 & $\ldots$ & $\ldots$ & 0.00 & 0.00 & 0.00 & \\
\hline 1 & 20 & 0 & 0 & $\ldots$ & 0.00 & 0.00 & 62.84 & $\ldots$ & 0.00 & 0.00 & 0.00 & 102.91 \\
\hline 2 & 0 & 20 & 0 & $\ldots$ & 0.00 & 0.00 & 41.75 & $\ldots$ & 0.00 & 0.00 & 0.00 & 52.94 \\
\hline 3 & 0 & 0 & 30,000 & 39.3 & 0.41 & 0.26 & $\ldots$ & $\ldots$ & 0.00 & 0.00 & 4.17 & $\ldots$ \\
\hline 4 & 20 & 0 & 30,000 & 19.4 & 0.90 & 0.81 & $\ldots$ & 43.4 & 0.51 & 0.35 & 32.33 & 70.55 \\
\hline 5 & 0 & 20 & 30,000 & 19.9 & 1 & 0.90 & $\ldots$ & 39.0 & 0.39 & 0.23 & 66.08 & 50.88 \\
\hline \multicolumn{13}{|l|}{ Contrasts $(P)^{\mathrm{h}}$} \\
\hline 3 vs. $(4,5)$ & & & & $<0.01$ & $<0.01$ & $<0.01$ & $\ldots$ & $\ldots$ & $-^{\mathrm{i}}$ & - & $<0.01$ & $\ldots$ \\
\hline 3 vs. 4 & & & & $<0.01$ & $<0.01$ & $<0.01$ & $\ldots$ & $\ldots$ & - & - & $<0.01$ & $\ldots$ \\
\hline 3 vs. 5 & & & & $<0.01$ & $<0.01$ & $<0.01$ & $\ldots$ & $\ldots$ & - & - & $<0.01$ & $\ldots$ \\
\hline 1 vs. 2 & & & & $\ldots$ & $\ldots$ & $\ldots$ & 0.04 & $\ldots$ & $\ldots$ & $\ldots$ & $\ldots$ & $<0.01$ \\
\hline 1 vs. 4 & & & & $\ldots$ & $\ldots$ & $\ldots$ & $\ldots$ & $\ldots$ & $\ldots$ & $\ldots$ & $\ldots$ & $<0.01$ \\
\hline 2 vs. 5 & & & & $\ldots$ & $\ldots$ & $\ldots$ & $\ldots$ & $\ldots$ & $\ldots$ & $\ldots$ & $\ldots$ & ns \\
\hline \multirow[t]{2}{*}{4 vs. 5} & & & & ns & ns & $\mathrm{ns}$ & $\ldots$ & $\mathrm{ns}$ & ns & ns & $<0.01$ & ns \\
\hline & & & & \multicolumn{4}{|c|}{ Cultivar PV 61} & \multicolumn{5}{|c|}{ Line CA 334.20 .4} \\
\hline 0 & 0 & 0 & 0 & $\ldots$ & 0.00 & 0.00 & $\ldots$ & $\ldots$ & 0.00 & 0.00 & 0.00 & $\ldots$ \\
\hline 1 & 20 & 0 & 0 & $\ldots$ & 0.00 & 0.00 & 96.55 & $\ldots$ & 0.00 & 0.00 & 0.00 & 84.53 \\
\hline 2 & 0 & 20 & 0 & $\ldots$ & 0.00 & 0.00 & 58.41 & $\ldots$ & 0.00 & 0.00 & 0.00 & 47.01 \\
\hline 3 & 0 & 0 & 30,000 & 21.3 & 0.68 & 0.47 & $\ldots$ & $\ldots$ & 0.00 & 0.00 & 15.87 & $\ldots$ \\
\hline 4 & 20 & 0 & 30,000 & 16.0 & 1 & 0.96 & $\ldots$ & 26.4 & 0.94 & 0.67 & 45.67 & $\ldots$ \\
\hline 5 & 0 & 20 & 30,000 & 16.7 & 1 & 0.96 & $\ldots$ & 28.3 & 0.83 & 0.58 & 47.60 & $\ldots$ \\
\hline \multicolumn{13}{|l|}{ Contrasts $(P)^{\mathrm{h}}$} \\
\hline 3 vs. $(4,5)$ & & & & $<0.01$ & $<0.01$ & $<0.01$ & $\ldots$ & $\ldots$ & - & - & $<0.01$ & $\ldots$ \\
\hline 3 vs. 4 & & & & $<0.01$ & $<0.01$ & $<0.01$ & $\ldots$ & $\ldots$ & - & - & $<0.01$ & $\ldots$ \\
\hline 3 vs. 5 & & & & $<0.01$ & $<0.01$ & $<0.01$ & $\ldots$ & $\ldots$ & - & - & $<0.01$ & $\ldots$ \\
\hline 1 vs. 2 & & & & $\ldots$ & $\ldots$ & $\ldots$ & $<0.01$ & $\ldots$ & $\ldots$ & $\ldots$ & $\ldots$ & 0.02 \\
\hline \multirow[t]{2}{*}{4 vs. 5} & & & & $\mathrm{~ns}$ & ns & $\mathrm{ns}$ & $\ldots$ & ns & ns & ns & ns & $\ldots$ \\
\hline & & & & \multicolumn{4}{|c|}{ Line CA 255.2.5.0 } & \multicolumn{5}{|c|}{ Line ICC $14216 \mathrm{~K}$} \\
\hline 0 & 0 & 0 & 0 & $\ldots$ & 0.00 & 0.00 & $\ldots$ & $\ldots$ & 0.00 & 0.00 & 0.00 & $\ldots$ \\
\hline 1 & 20 & 0 & 0 & $\ldots$ & 0.00 & 0.00 & 80.92 & $\ldots$ & 0.00 & 0.00 & 0.00 & 76.63 \\
\hline 2 & 0 & 20 & 0 & $\ldots$ & 0.00 & 0.00 & 46.47 & $\ldots$ & 0.00 & 0.00 & 0.00 & 50.62 \\
\hline 3 & 0 & 0 & 30,000 & 26.7 & 0.98 & 0.77 & $\ldots$ & $\ldots$ & 0.00 & 0.00 & 13.37 & $\ldots$ \\
\hline 4 & 20 & 0 & 30,000 & 23.7 & 1 & 0.95 & $\ldots$ & $\ldots$ & 0.00 & 0.00 & 41.95 & 63.11 \\
\hline 5 & 0 & 20 & 30,000 & 22.9 & 1 & 0.93 & $\ldots$ & $\ldots$ & 0.00 & 0.00 & 75.67 & 48.29 \\
\hline \multicolumn{13}{|l|}{ Contrasts $(P)^{\mathrm{h}}$} \\
\hline 3 vs. $(4,5)$ & & & & ns & ns & $<0.01$ & $\ldots$ & $\ldots$ & $\ldots$ & $\ldots$ & $<0.01$ & $\ldots$ \\
\hline 3 vs. 4 & & & & $\mathrm{~ns}$ & $\mathrm{~ns}$ & 0.01 & $\ldots$ & $\ldots$ & $\ldots$ & $\ldots$ & $<0.01$ & $\ldots$ \\
\hline 3 vs. 5 & & & & ns & ns & 0.01 & $\ldots$ & $\ldots$ & $\ldots$ & $\ldots$ & $<0.01$ & $\ldots$ \\
\hline 1 vs. 2 & & & & $\ldots$ & $\ldots$ & $\ldots$ & $<0.01$ & $\ldots$ & $\ldots$ & $\ldots$ & $\cdots$ & ns \\
\hline 1 vs. 4 & & & & $\ldots$ & $\ldots$ & $\ldots$ & $\ldots$ & $\ldots$ & $\ldots$ & $\ldots$ & $\ldots$ & ns \\
\hline 2 vs. 5 & & & & $\ldots$ & $\ldots$ & $\ldots$ & $\ldots$ & $\ldots$ & $\ldots$ & $\ldots$ & $\ldots$ & ns \\
\hline 4 vs. 5 & & & & ns & $\mathrm{ns}$ & $\mathrm{ns}$ & $\ldots$ & $\ldots$ & $\ldots$ & $\ldots$ & $<0.01$ & ns \\
\hline
\end{tabular}

${ }^{a}$ Data are the means of results for 10 replicate plants per treatment combination.

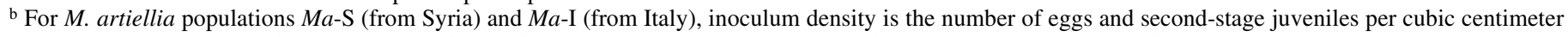
of soil. For F. oxysporum f. sp. ciceris race 5 (Foc-5), inoculum density is the number of chlamydospores per gram of soil.

c $I P=$ incubation period, expressed as the number of days from inoculation until $D I I>0$.

${ }^{\mathrm{d}} D I I=$ disease intensity index, calculated on the last day of assessment, 62 days after inoculation.

e SAUDPC = area under the disease progress curve standardized by duration (in days) of the epidemic.

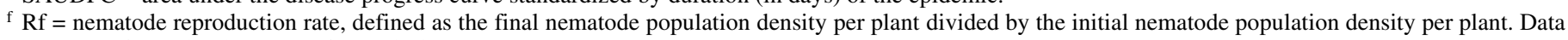
were transformed to $\log (x+1)$ for analysis.

g Not tested.

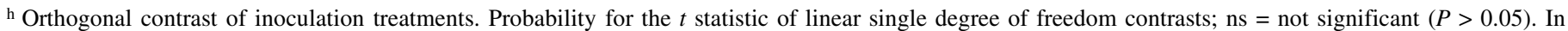
plants with partial resistance to Fusarium wilt, severe impairment of most of the root system of wilted plants made it impossible to assess nematode reproduction in and fungal colonization of root tissues, and consequently some contrasts could not be made.

i The comparison was not performed, to avoid the use of zero in the orthogonal contrast. 


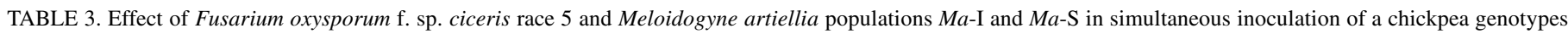
with partial resistance and genotypes with complete resistance to Fusarium wilt in the third growth chamber experiment ${ }^{\mathrm{a}}$

\begin{tabular}{|c|c|c|c|c|c|c|c|c|}
\hline \multirow{2}{*}{$\begin{array}{l}\text { Inoculation } \\
\text { treatment }\end{array}$} & \multicolumn{3}{|c|}{ Inoculum density ${ }^{\mathrm{b}}$} & \multirow[b]{2}{*}{$I P^{\mathrm{c}}$} & \multirow[b]{2}{*}{$D I I^{\mathrm{d}}$} & \multirow{2}{*}{\multicolumn{2}{|c|}{$\begin{array}{c}10^{4} \mathrm{CFU} \mathrm{g}^{-1} \\
\text { of roots }\end{array}$}} & \multirow[b]{2}{*}{$\operatorname{Rf}^{f}$} \\
\hline & $M a-\mathrm{S}$ & $M a-\mathrm{I}$ & Foc-5 & & & & & \\
\hline & & & & \multicolumn{5}{|c|}{ Cultivar PV 61 (partial resistance to Fusarium wilt) } \\
\hline 0 & 0 & 0 & 0 & $\ldots g$ & 0.00 & 0.00 & 0.00 & . . . \\
\hline 1 & 20 & 0 & 0 & $\ldots$ & 0.00 & 0.00 & 0.00 & 97.10 \\
\hline 2 & 0 & 20 & 0 & $\ldots$ & 0.00 & 0.00 & 0.00 & 61.02 \\
\hline 3 & 0 & 0 & 3,000 & 20.7 & 0.54 & 0.46 & 49.78 & . . \\
\hline 4 & 20 & 0 & 3,000 & 20.3 & 0.99 & 0.80 & . . . & $\ldots$ \\
\hline 5 & 0 & 20 & 3,000 & 22.3 & 0.89 & 0.75 & . . & $\ldots$ \\
\hline 6 & 0 & 0 & 30,000 & 21.0 & 0.71 & 0.58 & 63.56 & $\ldots$ \\
\hline 7 & 20 & 0 & 30,000 & 19.0 & 1 & 0.89 & . . . & $\ldots$ \\
\hline 8 & 0 & 20 & 30,000 & 17.7 & 1 & 0.91 & . . . & . . \\
\hline \multicolumn{9}{|l|}{ Contrasts $(P)^{\mathrm{h}}$} \\
\hline 3 vs. $(4,5)$ & & & & ns & $<0.01$ & $<0.01$ & . . & $\ldots$ \\
\hline 6 vs. $(7,8)$ & & & & $\mathrm{ns}$ & $<0.01$ & $<0.01$ & . . & . . \\
\hline 1 vs. 2 & & & & $\ldots$ & . . & . . & . . & $<0.01$ \\
\hline 1 vs. $(4,7)$ & & & & $\ldots$ & .. & . . & . . & . . \\
\hline 2 vs. $(5,8)$ & & & & $\ldots$ & $\ldots$ & $\ldots$ & . . & . . . \\
\hline
\end{tabular}

\begin{tabular}{|c|c|c|}
\hline 0 & 0 & 0 \\
\hline 1 & 20 & 0 \\
\hline 2 & 0 & 20 \\
\hline 3 & 0 & 0 \\
\hline 4 & 20 & 0 \\
\hline 5 & 0 & 20 \\
\hline 6 & 0 & 0 \\
\hline 7 & 20 & 0 \\
\hline 8 & 0 & 20 \\
\hline \multicolumn{3}{|l|}{ Contrasts $(P)^{\mathrm{h}}$} \\
\hline \multicolumn{3}{|l|}{3 vs. $(4,5)$} \\
\hline \multicolumn{3}{|l|}{6 vs. $(7,8)$} \\
\hline \multicolumn{3}{|l|}{1 vs. 2} \\
\hline \multicolumn{3}{|l|}{1 vs. $(4,7)$} \\
\hline 2 vs. $(5,8)$ & & \\
\hline
\end{tabular}

\begin{tabular}{|c|c|c|c|c|c|}
\hline 0 & $\ldots$ & 0.00 & 0.00 & 0.00 & \\
\hline 0 & $\ldots$ & 0.00 & 0.00 & 0.00 & 98.83 \\
\hline 0 & . . & 0.00 & 0.00 & 0.00 & 61.37 \\
\hline 3,000 & . . & 0.00 & 0.00 & 1.81 & $\ldots$ \\
\hline 3,000 & . . & 0.00 & 0.00 & 6.44 & 85.19 \\
\hline 3,000 & . . & 0.00 & 0.00 & 6.30 & 75.55 \\
\hline 30,000 & . . & 0.00 & 0.00 & 2.35 & \\
\hline 30,000 & 33.4 & 0.72 & 0.60 & 29.63 & 115.48 \\
\hline 30,000 & 37.1 & 0.74 & 0.55 & 20.15 & 71.28 \\
\hline & . . & $-^{\mathrm{i}}$ & - & $<0.01$ & $\ldots$ \\
\hline & . . & - & - & $<0.01$ & $\ldots$ \\
\hline & $\ldots$ & $\ldots$ & $\cdots$ & $\cdots$ & $<0.01$ \\
\hline & . . & . . & . . & . . & ns \\
\hline & . . & $\ldots$ & . . & . . . & ns \\
\hline
\end{tabular}

0
1
2
3
4
5
6
7
8
Contrasts $(P)^{\mathrm{h}}$
3 vs. $(4,5)$
6 vs. $(7,8)$
1 vs. 2
1 vs. $(4,7)$
2 vs. $(5,8)$

$\begin{array}{rrr}0 & 0 & \\ 20 & 0 & \\ 0 & 20 & 3,000 \\ 0 & 0 & 3,000 \\ 20 & 0 & 3,000 \\ 0 & 20 & 30,000 \\ 0 & 0 & 30,000 \\ 20 & 0 & 30,000 \\ 0 & 20 & \end{array}$

0
0
0
3,000
3,000
3,000
30,000
30,000
30,000

$\begin{array}{cc} & \text { Line CA } 334 \\ \ldots . & 0.00 \\ \ldots & 0.00 \\ \ldots . & 0.00 \\ 23.6 & 0.00 \\ 26.6 & 0.8 \\ 23.0 & 0.7 \\ 24.1 & 0.0 \\ & 0.9 \\ & \end{array}$

Fusarium wilt)

\begin{tabular}{|c|c|c|c|}
\hline 0.00 & 0.00 & 0.00 & \\
\hline 0.00 & 0.00 & 0.00 & 73.74 \\
\hline 0.00 & 0.00 & 0.00 & 53.72 \\
\hline 0.00 & 0.00 & 21.63 & \\
\hline 0.80 & 0.69 & 44.12 & 68.59 \\
\hline 0.73 & 0.65 & 70.18 & 47.68 \\
\hline 0.00 & 0.00 & 14.30 & \\
\hline 0.91 & 0.72 & 53.43 & 64.33 \\
\hline 0.86 & 0.70 & 34.46 & 34.76 \\
\hline - & - & $<0.01$ & $\ldots$ \\
\hline- & - & . . . & . . \\
\hline . . & $\ldots$ & . . . & 0.04 \\
\hline . . & . & . . . & ns \\
\hline . . & $\ldots$ & . . . & ns \\
\hline
\end{tabular}

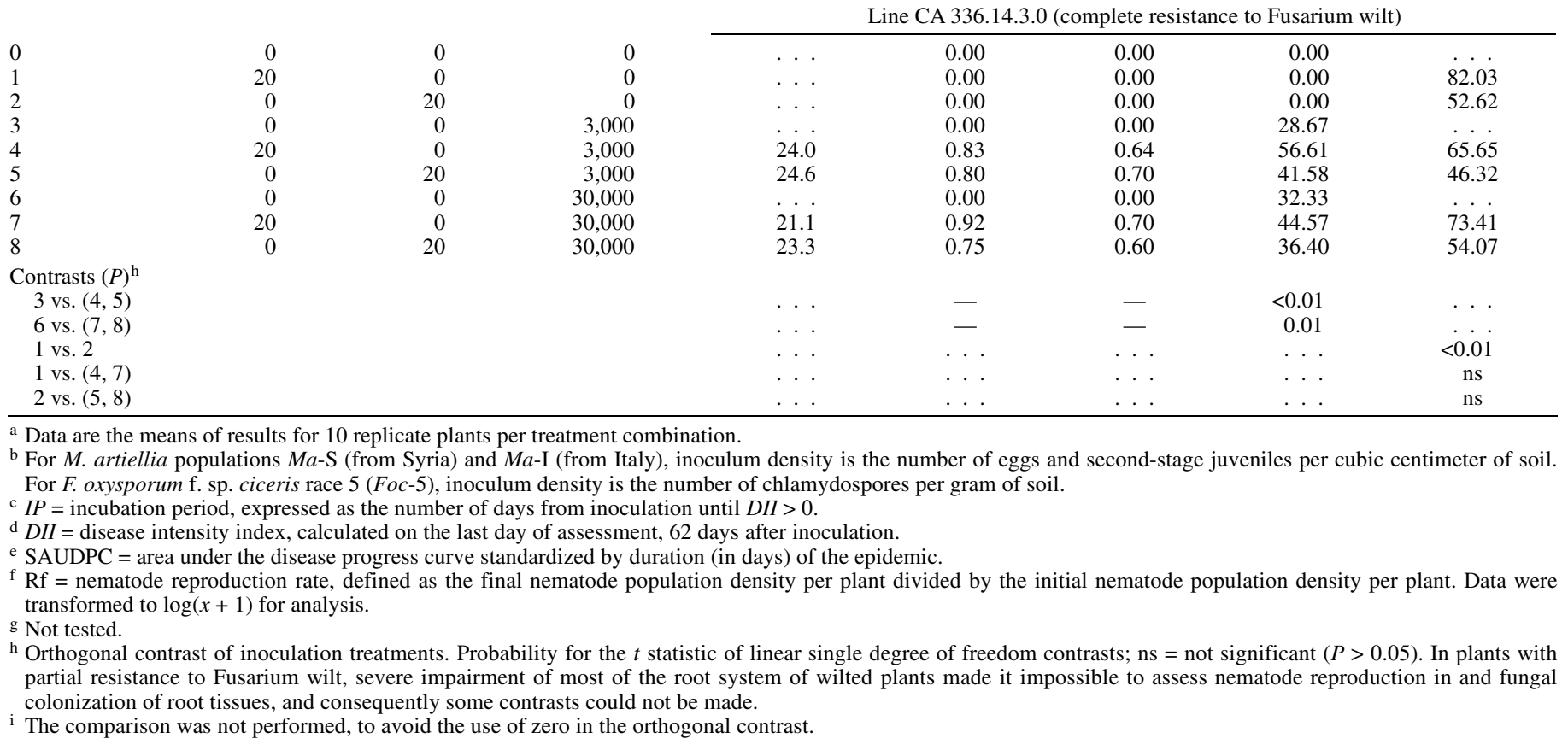


this study, except in cultivar CPS 1 , in which a significant increase in Fusarium wilt severity occurred only with $F$. oxysporum f. sp. ciceris race 5 at the high inoculum density. Also, and more important, our results suggest that coinfection with the two pathogens can overcome complete resistance to $F$. oxysporum f. sp. ciceris race 5 in some genotypes (CA 334.20.4, CA 336.14.3.0, and UC 27 , but not ICC $14216 \mathrm{~K}$ ) and that the breakdown of such resistance occurs irrespective of the initial inoculum density of the fungus and the geographic origin of the nematode, i.e., CA 334.20.4, CA 336.14.3.0, or required a high inoculum density of F. oxysporum f. sp. ciceris race 5 (cultivar UC 27). Thus, while the geographic origin of $M$. artiellia populations did not influence the reaction to $F$. oxysporum f. sp. ciceris race 5 in any of the tested chickpea genotypes, the nature of complete resistance to $F$. oxysporum $\mathrm{f}$. sp. ciceris race 5 in a particular host genotype and the fungal inoculum density influenced the breakdown of complete resistance to Fusarium wilt. In that regard our results agree with those of Uma Maheshwari et al. $(45,46)$, who reported a variable host response to coinfection by the root-knot nematode $M$. javanica and $F$. oxysporum f. sp. ciceris (probably race 1 ) in 53 chickpea genotypes resistant to Fusarium wilt.

The variation in the nematode-induced breakdown of resistance to Fusarium wilt observed in our study may be due to differences in the genetic background of the resistant chickpea genotypes. Fusarium wilt resistance in UC 27 is derived from the resistant chickpea line L 1186 (3,41), while resistance in CA 334.20.4 and CA 336.14.3.0 is from line ICCL 81001 (34). Line ICC $14216 \mathrm{~K}$, which appears to be of Mexican origin (37), was obtained from the Genetic Resources Unit of the International Crops Research Institute for the Semi-Arid Tropics (ICRISAT) for multilocation Fusarium wilt resistance testing in Spain. ICC 14216 K, CA 334.20.4, and CA 336.14.3.0 have shown complete and consistent resistance to $F$. oxysporum f. sp. ciceris race 5 in repeated resistance screening under both artificial and field conditions (34; R. M. Jiménez-Díaz, unpublished data).

Interactions between Meloidogyne spp. and several formae speciales of $F$. oxysporum have been studied in several crop species, more than any other fungus-nematode combination $(1,14,18-20$, 42). In those studies it was demonstrated that root-knot nematodes may not be able to overcome resistance to the fungal pathogen in all situations, especially if the host cultivars carry high levels of resistance to Fusarium wilt $(1,5)$. It has been emphasized that interactions between soilborne fungi and root-knot nematodes are biological and physiological rather than physical (30). Therefore, modification of Fusarium wilt incidence or severity by nematode infection should be expected to be related to the specific combination of plant genotype, nematode, and fungal pathogen $(5,30)$.

The inoculum densities of $F$. oxysporum $\mathrm{f}$. sp. ciceris race 5 and $M$. artiellia used in our study may be higher than those normally found in soil in chickpea-growing areas (10; R. M. Jiménez-Díaz, unpublished data) and higher than the optimum level for the development of Fusarium wilt $(29,32)$. However, those inoculum densities were needed to produce measurable and consistent $\mathrm{Fu}-$ sarium wilt in partially resistant chickpea genotypes and to allow us to demonstrate the potential for $M$. artiellia infections to erode or break down Fusarium wilt resistance.

On the basis of our results, we suggest that infection by $M$. artiellia affects the physiology of some chickpea genotypes in such a way that there is total or partial interference with the expression of the resistant reaction to $F$. oxysporum f. sp. ciceris race 5 (i.e., gene expression is rendered ineffective by disruption at the cellular or tissue level). In addition, giant cells induced by root-knot nematodes and the surrounding parenchyma cells are maintained by the nematodes in a perpetual juvenile state with high metabolic activity. That state may delay the rate of maturation or suberization of other vascular tissues, a condition that may assist the fungus in penetrating the xylem and becoming established in it $(15,49)$. Furthermore, the differential response of resistant chick- pea genotypes to coinfection with $F$. oxysporum f. sp. ciceris race 5 and $M$. artiellia may be related to the results of several other studies in that recessive and polygenic resistance to formae speciales of Fusarium oxysporum are more commonly overcome by nematode infection than that conferred by single dominant genes $(17,30,50)$. Resistance to Fusarium wilt in chickpea appears to be controlled by at least three independent loci, designated $\mathrm{H} 1, \mathrm{H} 2$, and H3. Partially recessive alleles in the homozygous form at either of the first two loci and the dominant allele at the third locus independently confer partial resistance to race 1 , but any two of those alleles together confer complete resistance $(47,48)$. Furthermore, resistance is unstable in coinfections with Meloidogyne spp. other than $M$. artiellia $(28,30,45,46)$. No information is available concerning the genetics of resistance to $F$. oxysporum f. sp. ciceris race 5 in the resistant genotypes used in this study.

Root coinfection with both $M$. artiellia (20 eggs and J2s per cubic centimeter of soil) and $F$. oxysporum f. sp. ciceris race 5 (3,000 or 30,000 chlamydospores per gram of soil) resulted in a higher number of propagules of $F$. oxysporum $\mathrm{f}$. sp. ciceris race 5 in roots of all cultivars with complete resistance to Fusarium wilt, compared with those in the absence of the nematode. These results differ from observations reported in other crops, in which the number of fungal propagules was not affected by coinfection with root-knot nematodes $(14,20,42)$. However, root colonization by the fungal pathogen was not quantified in most studies of interactions of root-knot nematodes and Fusarium wilt pathogens $(1,9,45,46)$, and thus comparison of results is hindered. On the basis of our results, we suggest that in chickpea plants with complete resistance to Fusarium wilt, infection of roots by $M$. artiellia might induce an increase in the release of substances that stimulate the germination of fungal propagules in the vicinity of the roots, thus increasing the chance of infection by the fungus. Another possibility is that infection by the nematode modifies the physiology of root cells in chickpea with complete resistance to Fusarium wilt in such a way that it facilitates more extensive colonization by $F$. oxysporum f. sp. ciceris race 5 .

Our results are consistent with previous reports in that infection of chickpea roots by $M$. artiellia induces very small galls $(\mathrm{Ma}-\mathrm{S})$ or no galls $(M a-\mathrm{I})(11,40)$. In the absence of the fungus, reproduction of $M$. artiellia $M a-\mathrm{S}$ was significantly higher than that of $M$. artiellia Ma-I in all chickpea genotypes tested except ICC 14216 $\mathrm{K}$ in the first and second experiments and UC 27 and CA 334.20.4 in the first experiment. However, in chickpea with partial complete resistance to Fusarium wilt, infection by $F$. oxysporum f. sp. ciceris race 5 usually did not modify the reproduction rate of $M$. artiellia, irrespective of the inoculum density of $F$. oxysporum $\mathrm{f}$. sp. ciceris race 5 or the geographic origin of the nematode population. An exception occurred in cultivar UC 27 in the second experiment, in which the reproduction rate of $M$. artiellia $M a-\mathrm{S}$ was significantly reduced in plants coinfected with the two pathogens. This suggests an intraspecific biological diversity of $M$. artiellia and agrees with reported high levels of variability in reproductive fitness in other Meloidogyne spp. $(36,38)$. The geographic isolation and limited capability for dispersal of $M$. artiellia suggest that variability in reproduction rate might be a consequence of divergent evolution under different environmental conditions. Although a small reduction in nematode reproduction rate was observed in plants infected with $F$. oxysporum f. sp. ciceris race 5, no significant differences were found between the two nematode populations, $M$. artiellia $M a-\mathrm{I}$ and $M a-S$, regardless of fungal inoculum density or host response. This result disagrees with other studies involving interactions between Meloidogyne spp. and Fusarium wilt pathogens, which reported a detrimental effect on nematode reproduction in plants with Fusarium wilt $(14,42,45,46)$. In those studies, reduction of nematode reproduction was attributable to extensive root damage caused by the fungus or to competition between the two organisms for available infection sites for invasion. However, we found that in chickpea cultivars with complete 
resistance to Fusarium wilt, nematode reproduction was not significantly influenced by fungal infection, irrespective of inoculum density. This apparent lack of effect on the two pathogens in chickpea suggests that the suitability of chickpea root tissues for infection prevents competition for available invasion loci.

In summary, the stability of resistance to Fusarium wilt in chickpea cultivars is compromised by coinfection with $F$. oxysporum f. sp. ciceris race 5 and $M$. artiellia, and this effect may vary with the source of plant resistance and the fungal inoculum density. Therefore, in breeding for stable Fusarium wilt resistance in chickpea, care should be taken to assess the reaction of the wilt resistance sources to $M$. artiellia and to coinfection with $M$. artiellia and $F$. oxysporum f. sp. ciceris. Further studies are needed to determine the mechanism of mechanisms underlying these plantnematode-fungus interactions. Knowledge of these interactions is essential for a better understanding of the epidemiology of Fusarium wilt in chickpea and for the development of efficient strategies for integrated management of the disease.

\section{ACKNOWLEDGMENTS}

This research was supported by grants AGF97-1479 and AGL200300640 from the Comisión Interministerial de Ciencia y Tecnología (CICYT), Madrid, Spain. The authors thank Blanca B. Landa for helpful comments on the manuscript and J. Martín-Barbarroja (Instituto de Agricultura Sostenible, Consejo Superior de Investigaciones Científicas [IASCSIC], Córdoba, Spain), for technical assistance. Seeds of CPS 1 and ICC 14216 K were kindly provided by H. A. van Rheenen (International Crops Research Institute for the Semi-Arid Tropics [ICRISAT], Hyderabad, India), and those of UC 27 were a gift from I. W. Buddenhagen (University of California, Davis).

\section{LITERATURE CITED}

1. Abawi, G. S., and Barker, K. R. 1984. Effects of cultivar, soil temperature, and population levels of Meloidogyne incognita on root necrosis and Fusarium wilt of tomatoes. Phytopathology 74:433-438.

2. Buddenhagen, I. W., and Workneh, F. 1988. Fusarium wilt of chickpea in California. (Abstr.). Phytopathology 78:1563.

3. Buddenhagen, I. W., Workneh, F., and Bosque-Pérez, N. 1988. Chickpea improvement and chickpea diseases in California. Int. Chickpea Newsl. 19:9-10.

4. Campbell, C. L., and Madden, L. V. 1990. Introduction to Plant Disease Epidemiology. John Wiley and Sons, New York.

5. Caperton, C. M., Martyn, R. D., and Starr, J. L. 1986. Effects of Fusarium inoculum density and root-knot nematodes on wilt resistance in summer squash. Plant Dis. 70:207-209.

6. Castillo, P., Gómez-Barcina, A., and Jiménez-Díaz, R. M. 1996. Plantparasitic nematodes associated with chickpea in southern Spain and effects of soil temperature on reproduction of Pratylenchus thornei. Nematologica 42:211-219.

7. Castillo, P., Mora-Rodríguez, M. P., Navas-Cortés, J. A., and JiménezDíaz, R. M. 1998. Interactions of Pratylenchus thornei and Fusarium oxysporum f. sp. ciceris on chickpea. Phytopathology 88:828-836.

8. Coolen, W. A. 1979. Methods for the extraction of Meloidogyne spp. and other nematodes from roots and soil. Pages 317-329 in: Root-Knot Nematodes (Meloidogyne Species): Systematics, Biology and Control. F. Lamberti and C. E. Taylor, eds. Academic Press, London.

9. De Vay, J. E., Gutierrez, A. P., Pullman, G. S., Wakeman, R. J., Garber, R. H., Jeffers, D. P., Smith, S. N., Goodell, P. B., and Roberts, P. A. 1997. Inoculum densities of Fusarium oxysporum f. sp. vasinfectum and Meloidogyne incognita in relation to the development of Fusarium wilt and the phenology of cotton plants (Gossypium hirsutum). Phytopathology 87: 341-346.

10. Di Vito, M., and Greco, N. 1988. The relationship between initial population densities of Meloidogyne artiellia and yield of winter and spring chickpea. Nematol. Mediterr. 16:163-166.

11. Di Vito, M., and Greco, N. 1988. Investigation on the biology of Meloidogyne artiellia. Rev. Nematol. 11:223-227.

12. Di Vito, M., Greco, N., Halila, H. M., Mabsoute, L., Labdi, M., Beniwal, S. P. S., Saxena, M. C., Singh, K. B., and Solh, M. B. 1994. Nematodes of cool-season food legumes in North Africa. Nematol. Mediterr. 22:3-10

13. Di Vito, M., Greco, N., and Zaccheo, G. 1985. On the host range of Meloidogyne artiellia. Nematol. Mediterr. 13:207-212.
14. France, R. A., and Abawi, G. S. 1994. Interaction between Meloidogyne incognita and Fusarium oxysporum f. sp. phaseoli on selected bean genotypes. J. Nematol. 26:467-474.

15. Francl, L. J., and Wheeler, T. A. Interaction of plant-parasitic nematodes with wilt-inducing fungi. Pages 79-103 in: Nematode Interactions. M. W. Khan, ed. Chapman and Hall, London.

16. Gomez, K. A., and Gomez, A. A. 1984. Statistical Procedures for Agricultural Research. 2nd ed. John Wiley and Sons, New York.

17. Goth, R. W., and Webb, R. E. 1981. Sources and genetics of host resistance in vegetable crops. Pages 377-411 in: Fungal Wilt Disease of Plants. M. E. Mace, A. A. Bell, and C. H. Beckman, eds. Academic Press, New York.

18. Harris, A. R., and Ferris, H. 1991. Interactions between Fusarium oxysporum f. sp. tracheiphilum and Meloidogyne spp. in Vigna unguiculata. 1. Effects of different inoculum densities on Fusarium wilt. Plant Pathol. 40:445-456.

19. Harris, A. R., and Ferris, H. 1991. Interactions between Fusarium oxysporum f. sp. tracheiphilum and Meloidogyne spp. in Vigna unguiculata. 2. Specificity of different taxa. Plant Pathol. 40:457-464.

20. Harris, A. R., and Ferris, H. 1991. Interactions between Fusarium oxysporum f. sp. tracheiphilum and Meloidogyne spp. in Vigna unguiculata. 3. Pathogenesis by F. o. trancheiphilum as affected by M. javanica and host cultivar. Plant Pathol. 40:465-475.

21. Haware, M. P. 1990. Fusarium wilt and other important diseases of chickpea in the Mediterranean area. Options Mediterr. Ser. Semin. 9:61-64.

22. Haware, M. P., and Nene, Y. L. 1982. Races of Fusarium oxysporum f. sp. ciceri. Plant Dis. 66:809-810.

23. Hussey, R. S., and Barker, K. R. 1973. A comparison of methods of collecting inocula of Meloidogyne spp., including a new technique. Plant Dis. Rep. 57:1025-1028.

24. Jalali, B. L., and Chand, H. 1992. Chickpea wilt. Pages 429-444 in: Plant Diseases of International Importance. Vol. 1, Diseases of Cereals and Pulses. U. S. Singh, A. N. Mukhopadhayay, J. Kumar, and H. S. Chaube, eds. Prentice-Hall, Englewood Cliffs, NJ.

25. Jiménez-Díaz, R. M., Crinó, P., Halila, M. H., Mosconi, C., and TraperoCasas, A. 1993. Screening for resistance to Fusarium wilt and Ascochyta blight in chickpea. Pages 77-96 in: Breeding for Stress Tolerance in Cool-Season Food Legumes. K. B. Singh and M. C. Saxena, eds. John Wiley and Sons, Chichester, England.

26. Jiménez-Díaz, R. M., Singh, K. B., Trapero-Casas, A., and TraperoCasas, J. L. 1991. Resistance in kabuli chickpeas to Fusarium wilt. Plant Dis. 75:914-918.

27. Jiménez-Díaz, R. M., Trapero-Casas, A., and Cabrera de la Colina, J. 1989. Races of Fusarium oxysporum f. sp. ciceris infecting chickpea in southern Spain. Pages 515-520 in: Vascular Wilt Diseases of Plants. NATO ASI Ser. H, Vol. 28. E. C. Tjamos and C. H. Beckman, eds. Springer-Verlag, Berlin.

28. Krishna Rao, V., and Krishnappa, K. 1996. Interaction of Fusarium oxysporum f. sp. ciceris with Meloidogyne incognita on chickpea in two soil types. Indian Phytopathol. 49:142-147.

29. Landa, B. B., Navas-Cortés, J. A., Hervás, A., and Jiménez-Díaz, R. M. 2001. Influence of temperature and inoculum density of Fusarium oxysporum f. sp. ciceris on suppression of Fusarium wilt of chickpea by rhizosphere bacteria. Phytopathology 91:807-816.

30. Mai, W. F., and Abawi, G. S. 1987. Interactions among root-knot nematodes and Fusarium wilt fungi on host plants. Annu. Rev. Phytopathol. 25:317-338.

31. Mani, A, and Sethi, C. L. 1987. Interaction of root-knot nematode, $M e-$ loidogyne incognita with Fusarium oxysporum f. sp. ciceris and $F$. solani on chickpea. Indian J. Nematol. 17:1-6.

32. Navas-Cortés, J. A., Alcalá-Jiménez, A. R., Hau, B., and Jiménez-Díaz, R. M. 2000. Influence of inoculum density of races 0 and 5 of Fusarium oxysporum f. sp. ciceris on development of Fusarium wilt in chickpea cultivars. Eur. J. Plant Pathol. 106:135-146.

33. Navas-Cortés, J. A., Hau, B., and Jiménez-Díaz, R. M. 1998. Effect of sowing date, host cultivar, and race of Fusarium oxysporum f. sp. ciceris on development of Fusarium wilt of chickpea. Phytopathology 88:13381346.

34. Navas-Cortés, J. A., Rodríguez-Jurado, D., and Jiménez-Díaz, R. M. 1998. Combined resistance against Didymella rabiei and races of Fusarium oxysporum f. sp. ciceris in kabuli chickpeas. Pages 124-125 in: 3rd European Conference on Grain Legumes. Opportunities for High Quality, Healthy and Added-Value Crops to Meet European Demands. European Association for Grain Legumes, Valladolid, Spain.

35. Nelson, P. E., Tousson, T. A., and Cook, R. J. 1981. Fusarium: Diseases, Biology and Taxonomy. Pennsylvania State University Press, University Park.

36. Noe, J. P. 1992. Variability among populations of Meloidogyne arenaria. J. Nematol. 24:404-414. 
37. Pundir, R. P. S., Reddy, K. N., and Mengesha, M. H. 1988. ICRISAT chickpea germplasm catalog: Passport information. International Crops Research Institute for the Semi-Arid Tropics, Patancheru, Andhra Pradesh, India.

38. Roberts, P. A., and Thomason, I. J. 1989. A review of variability in four Meloidogyne spp. measured by reproduction on several hosts including Lycopersicon. Agric. Zool. Rev. 3:225-252.

39. Sikora, R. A. 1987. Plant parasitic nematodes of wheat and barley in temperate and temperate semiarid regions-A comparative analysis. Pages 46-68 in: Proc. Workshop on Nematodes Parasitic to Cereals and Legumes in Temperate Semiarid Regions held at Larnaca (Cyprus). M. C. Saxena, R. A. Sikora, and J. P. Srivastava, eds. Aleppo, Syria.

40. Sikora, R. A., and Greco, N. 1990. Nematode parasites of food legumes. Pages 181-235 in: Plant Parasitic Nematodes in Subtropical and Tropical Agriculture. M. Luc, R. A. Sikora, and J. Bridge, eds. CAB International, Wallingford, England.

41. Singh, K. B. 1987. Chickpea breeding. Pages 127-162 in: The Chickpea. M. C. Saxena and K. B Singh, eds. CAB International, Wallingford, England.

42. Starr, J. L., Jeger, M. J., Martyn, R. D., and Schilling, K. 1989. Effects of Meloidogyne incognita and Fusarium oxysporum f. sp. vasinfectum on plant mortality and yield of cotton. Phytopathology 79:640-646.

43. Tobar Jiménez, A. 1973. Nematodes de los secanos de la comarca de Al- hama. I. Niveles de población y cultivos hospedadores. Rev. Iber. Parasitol. 33:525-556.

44. Trapero-Casas, A., and Jiménez-Díaz, R. M. 1985. Fungal wilt and root rot diseases of chickpea in southern Spain. Phytopathology 75:1146-1151.

45. Uma Maheshwari, T., Sharma, S. B., Reddy, D. D. R., and Haware, M. P. 1995. Co-infection of wilt-resistant chickpeas by Fusarium oxysporum $\mathrm{f}$. sp. ciceris and Meloidogyne javanica. J. Nematol. 27:649-653.

46. Uma Maheshwari, T., Sharma, S. B., Reddy, D. D. R., and Haware, M. P. 1997. Interaction of Fusarium oxysporum f. sp. ciceri and Meloidogyne javanica on Cicer arietinum. J. Nematol. 29:117-126.

47. Upadhyaya, H. D., Haware, M. P., Kumar, J., and Sminthson, J. B. 1983. Resistance to wilt in chickpea. I. Inheritance of late-wilting in response to race 1. Euphytica 32:447-452.

48. Upadhyaya, H. D., Sminthson, J. B., Haware, M. P., and Kumar, J. 1983. Resistance to wilt in chickpea. II. Further evidence for two genes for resistance to race 1. Euphytica 32:749-755.

49. Webster, J. M. 1985. Interaction of Meloidogyne with fungi on crop plants. Pages 183-192 in: An Advanced Treatise on Meloidogyne. Vol. 1. J. N. Sasser and C. C. Carter, eds. North Carolina State University Graphics, Raleigh.

50. Wilhelm, S. 1981. Sources and genetics of host resistance in field and fruit crops. Pages 299-376 in: Fungal Wilt Disease of Plants. M. E. Mace, A. A. Bell, and C. H. Beckman, eds. Academic Press, New York. 